\title{
Fabrication of chitosan-coated mixed spinel ferrite integrated with graphene oxide (GO) for magnetic extraction of viral RNA for potential detection of SARS-CoV-2
}

\author{
Vijay Singh $^{1}$ (]) Khalid Mujasam Batoo ${ }^{2}$ (I) $\cdot$ Mahavir Singh $^{1}$ (])
}

Received: 21 July 2021 / Accepted: 4 November 2021 / Published online: 27 November 2021

(C) The Author(s), under exclusive licence to Springer-Verlag GmbH, DE part of Springer Nature 2021

\begin{abstract}
Genetic variants of the COVID-19 causative virus have been arising and circulating globally. In many countries, especially in developing ones with a huge population, vaccination has become one of the major challenges. SARS-CoV-2 variants' fast transmission rate has an upsurge in the COVID cases, leading to more stress on health systems. In the current COVID19 scenario, there is the requirement of more adequate diagnostic approaches to check the COVID-19 spread. Out of many diagnostic approaches, a magnetic nanoparticle-based reverse transcription polymerase chain reaction could be nontrivial. The use of magnetic nanoparticles is to separate nucleic acid of SARS-CoV-2 from the patient samples and apply for SARSCoV-2 detection in an easy and more effective way. Herein, the magnetic nanoparticles are synthesized using the solgel autocombustion methods and then successfully coated with biopolymer (chitosan) using ultrasonication. Chitosan-coated nanoparticles are successfully integrated into the graphene oxide sheets to introduce carboxyl groups. Crystallite size calculation, morphological and magnetic studies of synthesized magnetic nanoparticles, and multifunctional magnetic nanoparticles are done using XRD, SEM, TEM, and VSM, respectively. Besides, the potentiality of the fabricated nanocomposites in RNA extraction protocol is also discussed with schematic representation.
\end{abstract}

Keywords Magnetic nanoparticles $\cdot$ Magnetic nanocomposite $\cdot$ SARS-COV-2 $\cdot$ COVID-19 $\cdot$ Spinel ferrite $\cdot$ Viral extraction

\section{Introduction}

Ensuing viral pandemic disease COVID-19 caused by an entirely unique coronavirus (nCoV) "SARS-CoV-2" continues to strike the medical and health sectors [1]. Multiple SARS-COV-2 variants like B.1.1.7, B.1.351, B.1.427, B.1.429, B.1.6172, N450K, S477N, etc., have worsened the things [1]. These variants can transmit more easily and quickly, resulting in more COVID-19 cases and potentially more deaths [2]. In countries with huge populations, the shortage of vaccines has become a serious challenge. Besides, the upper possibilities of further SARS-CoV-2 genome mutation are a major challenge within the vaccine or adequate drug

Vijay Singh

bharmoriavij.93@gmail.com

1 Department of Physics, Himachal Pradesh University, Shimla 171005, India

2 King Abdullah Institute for Nanotechnology, King Saud University, P.O. Box-2455, Riyadh 11451, Saudi Arabia development against COVID-19 [3]. Thus, aggressive surveillance is required. Early diagnosis of COVID-19 patients is the efficient way to monitor SARS-CoV-2 spread in time and space, thereby tracking and mitigating the COVID-19 outbreak. After the successful investigation of SARS-CoV-2 genome sequences, diverse sorts of COVID-19 diagnostic approaches are developed, out of which reverse transcription polymerase chain reaction (RT-PCR) is the most sensitive and specific one [4]. Despite the advantages of RT-PCR tests, these tests have limitations like long processing time, high cost, trained operators, and false results, which hinder the potentiality of RT-PCR tests for potential detection and control of the COVID-19 outbreak [5]. These major bottlenecks in conventional detection techniques are often avoided with methodological simplification. Magnetic separation (MS) is an increasingly significant technique for molecular biology. The MS technique is productive for purification at the commercial level $[6,7]$. Recently, target-specific magnetic nanocomposites (MNCs) have been developed which in conjugation with an adequate buffer system could make speedy and efficient purification. Centrifugation steps are 
dodged. Besides, MS protocol provides for facile automation of the entire process and therefore the separation of desired biological entities from the larger sample volumes. MNPs (ferrites) are easy to synthesize, have ecofriendly nature, have minimal toxicity, and have unusual physicochemical characteristics $[8,9]$. The functionalization of MNPs with biopolymers/synthetic polymers or with graphene and its derivatives (graphene oxide (GO) and reduced graphene oxides (rGO)) increases the prior mentioned characteristics of MNPs [10, 11]. Thus, functionalized MPNs behold the potential to reinforce testing availability and efficiency, thereby benefiting the patient care and COVID-19 infection control. Somvanshi et al. synthesized multifunctional ceramic $\mathrm{ZnFe}_{2} \mathrm{O}_{4}$ (ZF) to help RNA extraction protocol for RT-PCR analysis [8]. Bare ZF NPs, synthesized through the solgel autocombustion method, were stepwise modified with amino $\left(-\mathrm{NH}_{2}\right)$ and carboxyl $(-\mathrm{COOH})$ groups using tetraethyl orthosilicate (TEOS), (3-aminopropyl)triethoxysilane (APTES), and -COOH-loaded polyvinyl alcohol (PVA). Zhao et al. synthesized multiple-COOH-loaded magnetic composite for MS of SARS-COV-2 RNA through one-step incubation and reported that MS-based protocol is the best technology than usual spin column one [12]. Navas-León D.G. et al. supporting Zhao et al. fabrication route has presented a 'simplified three-step method' for giant production of MNPs for SARS-COV-2 virus RNA separation [4]. Sree Chitra Tirunal Institute for Medical Sciences and Technology (SCTIMST) (India) reported developing an innovative MNPs-assisted viral RNA extraction kit named "Chitra Magna." In this kit, MNPs are used to capture and concentrate on the viral RNA of SARS-CoV-2 from the COVID patient's sample [13]. Researchers from Norwegian University of Science and Technology (NTNU) used silica-modified MNPs to extract SARS-CoV-2 RNA. They reported that magnetic-assisted COVID-19 test is more efficient than commercial tests [14]. Klein et al. provided a technique in which magnetic beads (MBs) are used to separate and concentrate on SARS-CoV-2 RNA for RT-qPCR and RT-LAMP [15]. In their study, they used Liquidator 96 pipetting system for magnetic extraction protocol. MBs are resuspended in a 96-well plate using liquidator. Kleinet et al. concluded that their protocol is suitable for RNA extraction of any type of virus from pharyngeal swabs [15]. Chitosan $(\mathrm{CH})$ and $\mathrm{GO}$ are found significant in inhibiting and detecting SARS-CoV-2 [16-19]. CH, a naturally abundant cationic polymer, is insoluble in an aqueous medium but soluble in a weakly acidic medium [20], majorly consisting of $-\mathrm{NH}_{2}$ and hydroxyl (-OH) groups, where $-\mathrm{NH}_{2}$ group gets converted into soluble $-\mathrm{NH}_{3}{ }^{+}$[21]. This biopolymer exhibits many meritorious properties likely non-toxicity, biodegradability, biocompatibility, and antimicrobial efficacy. Besides, it has a good chelating effect, especially when solubilizes within the weakly ethanoic acid medium [20]. These admirable properties of $\mathrm{CH}$ motivated researchers to utilize it against SARS-CoV-2. The study conducted by Gulimiran et al. has revealed the potential of $\beta-\mathrm{CH}$ to strongly bind to the SARS-CoV-2s' receptor-binding domain (RBD) [22]. Farzin et al. have fabricated a nanometric gas sensor using CPE-HT18C6(Ag)/chitosan/SiQDs@PAMAM/probe for the voltammetric determination of SARS-CoV-2 RdRP sequence (RdRP_SARSr-P2) [17]. Thus, fabricated sensor possesses a broad linear range of detection, better selectivity, and a low limit of detection (LOD) [17]. Graphene and its derivatives too have a lot to offer against COVID-19, attributing to their unique properties like thermomechanical durability, piezoelectricity, large surface area, strong antiviral potency, and so on $[23,24]$. Graphene derivative $\mathrm{GO}$ with the abundance of oxygen-containing $-\mathrm{OH}$, carbonyl $(\mathrm{C}=\mathrm{O})$, epoxide, and $-\mathrm{COOH}$ functional groups on its basal planes and availability of strong negative surface charge can be used to fabricate better RNA-extracted protocol against SARS-COV-2 [4, 19]. Among MNPs, ceramics (spinel ferrites (SFs)) have allured substantial interest attributing to their unusual physicochemical characteristics [25]. Among them, lithium zinc ferrite (LZFO) is one of the foremost important inverse spinel ferrites owing to its high saturation magnetization, easy preparation, and high adsorption efficacy [10]. About 30-40\% zinc doping end in a maximum magnetization increases, and over this, it starts to decrease [26].

On the basis of the information gathered from the literature, over SARS-CoV-2 RNA extraction protocols (especially for RT-PCR) as mentioned above, two crucial steps are there for the development of MS protocol. The first step is to develop MNPs with high magnetic saturation value, followed by the second step, i.e., introduction of suitable functional groups which can bind strongly to SARS-CoV-2 RNA. All the protocols that have been developed so far are modified with $-\mathrm{NH}_{2},-\mathrm{COOH}$ groups or have $-\mathrm{OH}$ groups. To introduce these groups, the functionalization techniques are time-consuming and used more chemicals. Point raised from here is there needed magnetic composites with strong binding efficiency and facile synthesis. Thus, MNC comprised of LZFO as magnetic core and $\mathrm{CH}-\mathrm{GO}$ as matrix has a greater possibility. LZFO can be prepared through numerous routes like top-down, bottom-up (chemical synthesis), or biosynthesis [27, 28]. One of the techniques is solgel autocombustion (chemical synthesis), an exothermic and self-ignition (low temperature) approach. In this, xerogel was procured from an aqueous sol, which having metal salts (oxidizer) and organic complexing agent (reductant) of interest undergoes thermally induced anionic redox reaction [29]. This lowtemperature technique provides good chemical uniformity (i.e., mingling of metal ions of craved composition at the molecular level); better purity and crystallinity; fine particle size and narrow particle size distribution [30, 31]. Besides, stoichiometry could be comfortably administered; the introduction of dopants into the end product is facile, simple 
accessories and synthesis process, shorter processing time, low external energy utilization (low-temperature requirement for ignition), and simple operating procedure [30, 32]. Herein, the prime intent is to synthesize diamagnetic $\mathrm{Zn}^{2+}$-doped lithium ferrite (LF) MNPs for the composition $\mathrm{Li}_{0.33} \mathrm{Zn}_{0.34} \mathrm{Fe}_{2.33} \mathrm{O}_{4}$ (LZFO) by the solgel autocombustion route. Afterward, the prepared nanosized LZFO particles are modified with the $-\mathrm{NH}_{2}$ groups through $\mathrm{CH}$ coating. In the end, CHLZFO biocomposite is integrated with GO matrix to introduce carboxyl groups by ultrasonication technique. Later on, synthesized LZFO and MNCs are examined for their structural, morphological, and magnetic characteristics. Besides, how MNC can be used in the magnetic separation of viral RNA is also discussed (theoretically).

\section{Experimental}

\subsection{Materials and chemicals}

Graphite flakes, hydrazine hydrate, sulfuric acid $\left(\mathrm{H}_{2} \mathrm{SO}_{4}\right)$, phosphoric acid $\left(\mathrm{H}_{3} \mathrm{PO}_{4}\right)$, potassium permanganate $\left(\mathrm{KMnO}_{4}\right)$, hydrogen peroxide $\left(\mathrm{H}_{2} \mathrm{O}_{2}\right)$, hydrochloric acid
(HCL), lithium nitrate $\left(\mathrm{LiNO}_{3}\right)$, zinc nitrate hexahydrate $\left(\mathrm{Zn}\left(\mathrm{NO}_{3}\right)_{2} \cdot 6 \mathrm{H}_{2} \mathrm{O}\right)$, iron nitrate nonahydrate $\mathrm{Fe}\left(\mathrm{NO}_{3}\right)_{3} \cdot 9 \mathrm{H}_{2} \mathrm{O}$, citric acid (CA) $\left(\mathrm{C}_{6} \mathrm{H}_{8} \mathrm{O}_{7}\right)$, ammonia, ethylene glycol (EG), ethanol, and chitosan were of analytical grade and used without further purification and treatment. All the chemicals were purchased from Central Drug House (P) Ltd. (CDH), Solan, India.

\subsection{Procedures}

\subsubsection{Synthesis of graphene oxide (GO)}

GO is synthesized by improved hummer method (see Fig. 1c: Schematic representation of improved hummer method for GO synthesis) [33]. A mixture of sulfuric acid and phosphoric acid $\left(\mathrm{H}_{2} \mathrm{SO}_{4} / \mathrm{H}_{3} \mathrm{PO}_{4}\right.$ at a vol. ratio of 9:1 $\left.(360: 40 \mathrm{~mL})\right)$ was prepared by stirring for $15 \mathrm{~min}$. Afterward, $1.5 \mathrm{~g}$ of graphite flakes was added. Next, $18.0 \mathrm{~g}$ of $\mathrm{KMnO} 4$ was slowly added into the mixture with continuous stirring. The prepared mixture was stirred for $72 \mathrm{~h}$. After $72 \mathrm{~h}$ of stirring, $3 \mathrm{ml}$ of $30 \%$ hydrogen peroxide $\left(\mathrm{H}_{2} \mathrm{O}_{2}\right)$ was added to end the reaction. Then, the mixture was put into eight separate 50 -ml centrifuge tubes for washing. The washing was done with $\mathrm{HCl}$ acid

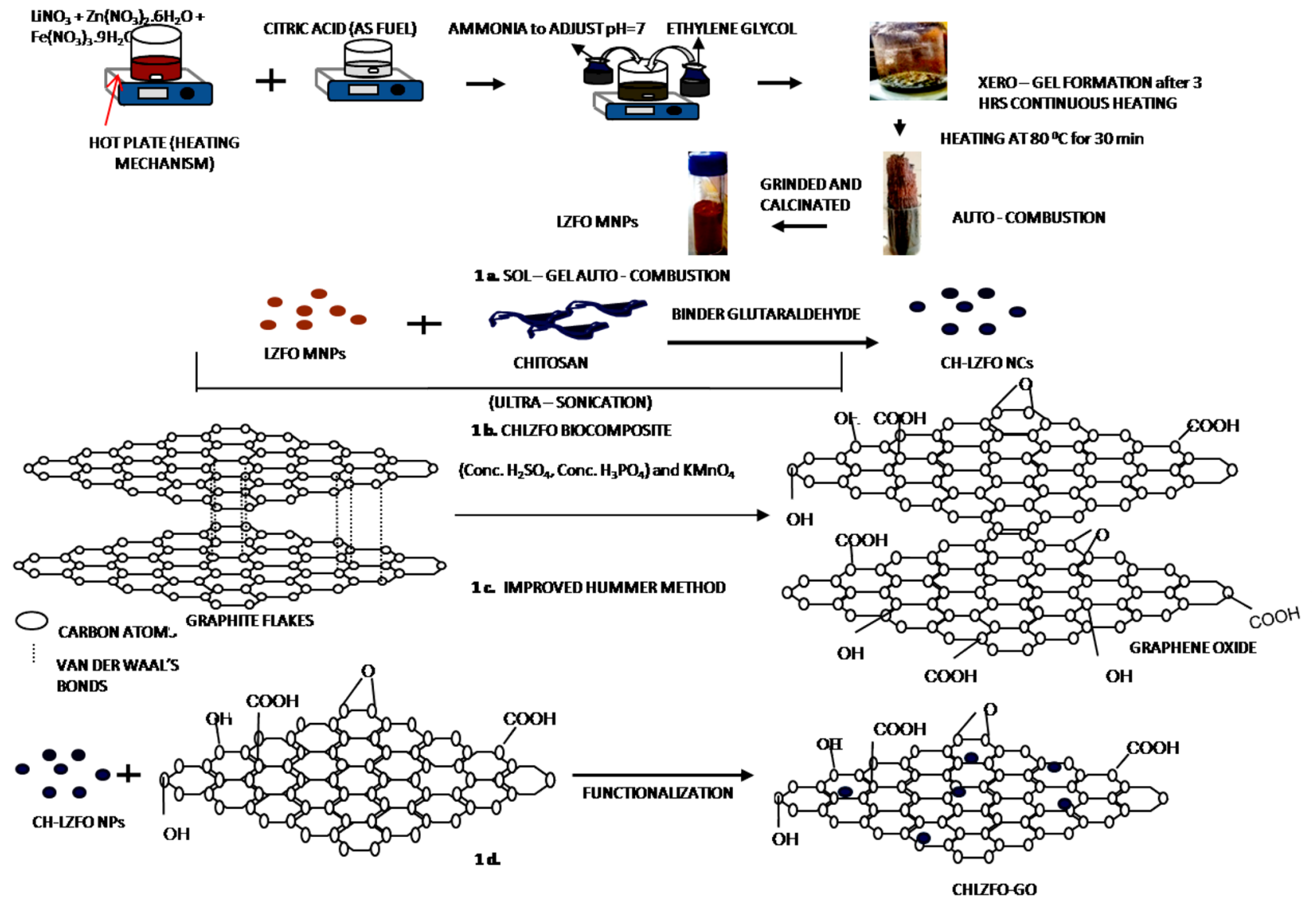

Fig. 1 Schematic representation of various methods used for: a sol-gel synthesis of LZFO, b ultra-sonication synthesis of CHLZFO biocomposite, $\mathbf{c}$ Improved Hummer method synthesis of GO, and d ultra-sonication synthesis of CHLZFO-GO nanocomposite 
and double distilled water alternately with the centrifugation at $5000 \mathrm{rpm}$ for $10 \mathrm{~min}$ for each washing step. Washing steps were repeated thrice. Lastly, the final product was dried in an oven at $80{ }^{\circ} \mathrm{C}$ for $24 \mathrm{~h}$.

\subsubsection{Synthesis of mixed lithium zinc ferrite}

Pristine MNPs of LZFO were fabricated by solgel combustion method shown in Fig. 1a: Schematic representation of solgel autocombustion route for fabrication of LZFO [34]. The analytical grade lithium nitrate $\left(\mathrm{LiNO}_{3}\right)$, zinc nitrate hexahydrate $\left(\mathrm{Zn}\left(\mathrm{NO}_{3}\right)_{2} \cdot 6 \mathrm{H}_{2} \mathrm{O}\right)$, and iron nitrate nonahydrate $\mathrm{Fe}\left(\mathrm{NO}_{3}\right)_{3} \cdot 9 \mathrm{H}_{2} \mathrm{O}$ were used as precursor materials. In stoichiometric amounts, these nitrate precursors were dissolved in double distilled water and stirred for $2 \mathrm{~h}$ to get a homogenous solution. Thereafter, during stirring equimolar citric acid (as fuel) was added to the solution which was first separately dissolved in double distilled water. The resulted solution $\mathrm{pH}$ was maintained about 7 using ammonia. Then, ethylene glycol $\left(\mathrm{C}_{2} \mathrm{H}_{6} \mathrm{O}_{2}\right)$ was added to the mixed solution and was heated at $80{ }^{\circ} \mathrm{C}$ under constant magnetic stirring to get dark-colored dried gel, i.e., viscous brown gel, followed by foaming of the gel. The foamy gel at $80^{\circ} \mathrm{C}$ caused its spontaneous ignition. The combustion reaction was completed within a few seconds, and loose powder was formed. This was crushed and ground thoroughly. The puffy, brown powder as-combusted was calcinated at $500{ }^{\circ} \mathrm{C}$ for $5 \mathrm{~h}$ to get pure LZFO.

\subsubsection{Ultrasonic synthesis of chitosan-coated LZFO NPs (CHLZFO nanocomposite)}

CHLZFO nanocomposite was fabricated by ultrasonication route (see Fig. 1b: Schematic procedure for CHLZFO) [35]. $0.5 \mathrm{~g}$ of $\mathrm{CH}$ was dissolved in $100 \mathrm{ml}$ of acetic acid (2wt\%) solution, and $5 \mathrm{~g}$ amount of LZFO was dispersed in $50 \mathrm{~mL}$ ethanol by ultrasonication for $2 \mathrm{~h}$. The prepared suspension was then added into the chitosan solution. Thereafter, the prepared mixture was sonicated for $2 \mathrm{~h}$. After that, $3 \mathrm{ml}$ (25\%) glutaraldehyde solution (as a cross-linker) was added and the solution was mechanically stirred for $30 \mathrm{~min}$ at $60{ }^{\circ} \mathrm{C}$ for better cross-link of the chitosan. Then, $\mathrm{pH}$ about 8 was adjusted by drop-wise addition of ammonia solution. The resulted precipitate was separated from the reaction mixture by filtration process, washed several times with double distilled water, and dried at $60^{\circ} \mathrm{C}$ for $10 \mathrm{~h}$ to obtain the chitosan-coated LZFO NPs.

\subsubsection{Ultrasonication preparation of CHLZFO-GO nanocomposite}

To prepare CHLZFO-GO nanocomposite, using ultrasonication method (see Fig. 1d: Schematic procedure for CHLZFOGO nanocomposites) 16:1 ratio of CHLZFO (800 mg) and
$\mathrm{GO}(5 \mathrm{mg})$ were separately taken in double distilled water and ultrasonicated for $1 \mathrm{~h}$ to get uniform dispersion of CHLZFO NPs and colloidal solution of GO. Thereafter, under continuous ultrasonication, the uniform dispersion of CHLZFO NPs was slowly added to the colloidal solution of GO. Finally, $2 \mathrm{~mL}$ (25\%) glutaraldehyde solution (as cross-linker) was slowly added into the prepared mixture which was then ultrasonicated for $1 \mathrm{~h}$. In the end, after three washes and simultaneous filtration, the obtained dark grayish red color precipitate was dried at $50{ }^{\circ} \mathrm{C}$ for $6 \mathrm{~h}$ to get the CHLZFO-GO nanocomposite.

\subsection{Characterization}

X-ray diffraction method was employed to authenticate the formation of GO, LZFO MNPs, CHLZFO, and CHLZFOGO MNCs. XRD instrument used was PANalytical X'Pert Pro X-ray diffractometer (India), using Cuk $\alpha 1$ radiation ( $\lambda=1.5406 \AA$ ) operating at working voltage of $45 \mathrm{kV}$ and working current of $40 \mathrm{~mA}$ in the $2 \theta$ range of $5.070-90.010^{\circ}$ at step size $0.02^{\circ}$. Both the lattice constant and the crystallite size for prepared samples were determined using Debye-Scherrer equation. Morphological studies were performed by JEM-2100F Field Emission Electron Microscope and JEOL JSM-7600F Field Emission Scanning Electron Microscope (FESEM) (Saudi Arabia). Furthermore, magnetic characterizations were studied using EV9 Vibrating Sample Magnetometer (EV9 VSM), MicroSense (India), by applying \pm 2 Tesla field at ambient temperature.

\section{Results and discussion}

\subsection{LZFO nanopowder by solgel autocombustion}

For solgel autocombustion, LZFO nanopowder nitrate salts are synthesized and used as precursors since these are easily soluble in water and can serve as low-temperature $\mathrm{NO}_{3}^{-}$ oxidant source for the preparation process [36]. Metal nitrates are of hygroscopic nature which means they can easily absorb moisture from their surroundings [37]. The selection of a proper complexing agent/fuel agent is significant as it governs the phase formation during the autocombustion process. Complexing agents can serve dual purposes as (1) a fuel for ignition (where it behaves as a reductant and can get easily oxidized by $\mathrm{NO}_{3}^{-}$ions) and (2) a chelating agent to form complex with metal ions [38]. The used complexing agent chelates metal ions by changing ionic radii and prevents their choosy precipitation to keep compositional uniformity among the constituents [38]. The ideal complexing agents should react moderately and generate non-carcinogenic gases [39]. Since hydrazine $\left(\mathrm{N}_{2} \mathrm{H}_{4}\right)$ is carcinogenic, it has used seldom as complexant [40]. In the current research, $\mathrm{C}_{6} \mathrm{H}_{8} \mathrm{O}_{7}$ is used as a complexing agent. $\mathrm{CA}$ is the persistently used 
complexing agent for the synthesis of an ample variety of ferrites through the solgel autocombustion technique. CA significance attributed to the factor that it is economical and exhibits - $\mathrm{COOH}$ groups and -OH groups [38]. Complexing agents having $-\mathrm{COOH}$ groups, $-\mathrm{OH}$ groups, and $-\mathrm{NH}_{2}$ groups are nontrivial for the water-soluble complex precursor preparation method [38]. The use of complexant in the synthesis procedure governs the temperature and rate of the reaction. Complexant deficiency may lower down the temperature and slows down the rate of reaction due to low heat generation during the reaction which can result in lessening of SFs' dimension, poor crystalline nature, phase purity, and specific area enhancement [40-43]. Thus, $\mathrm{C}_{6} \mathrm{H}_{8} \mathrm{O}_{7}$ used in the current research is equimolar with metal nitrates. The addition of $\mathrm{CA}$ as a complexant is usually followed by the addition of ammonia $\left(\mathrm{NH}_{4} \mathrm{OH}\right)$. In the absence of $\mathrm{NH}_{4} \mathrm{OH}$, CA will merely act as a fuel. $\mathrm{NH}_{4} \mathrm{OH}$ addition controls oxygen balance (ratio of metal salts to CA), improves the complexation between metal cations and citrates, and enhances the combustion rate of the reaction. This could result in the formation of a porous 3D network structure in the nitrate-citrate gel [44]. The little amount of $\mathrm{NH}_{4} \mathrm{OH}$ added is administered by maintaining solution $\mathrm{pH}$. Waqas et al. reported that $\mathrm{pH}=6$ is the most favorable value for spinel ferrite synthesis [45]. However, neutral $\mathrm{pH}(=7)$ has been chosen by most of the researchers for the formation of spinel ferrite from the nitrate-citrate xerogel. In the present research, also $\mathrm{pH}=7$ is being chosen. $\mathrm{C}_{2} \mathrm{H}_{6} \mathrm{O}_{2}$ is used to terminate the reaction. Its addition to the mixed solution of nitrates and citrates may result in the formation of a single-phase LZFO by decreasing combustion temperature and increasing heat generation in the reaction [46]. In the reaction, EG acts as a gelating reagent and forms an organic ester by forming bonds with citrates $[47,48]$. Properties of LZFO nanopowder strongly depend on the heating mechanism used [49, 50]. In this work, a hotplate is used as a heating source. Heating through a hotplate could result in particles of small and agglomerate sizes with a high area of surface [50]. During the burning of xerogel, gases in large volumes were released, which could have resulted in a great mass loss and led to the formation of brown-colored fluffy LZFO nanopowders [40, 51]. Then, the fluffy (porous) LZFO powder was calcinated which formed compact LZFO MNPs (see Fig. 1a).

\subsection{Proposed mechanism of ultrasonication synthesis of CHLZFO-GO magnetic nanocomposites with basic mechanism of ultrasonication}

\subsubsection{Basics of ultrasonication}

Ultrasonication technique works on the mechanism acoustic cavitation (AC), where high-frequency longitudinal waves with a frequency range of $20 \mathrm{kHz}$ to a few $\mathrm{MHz}$ are used. Ultrasound-induced cavitation comprises three significant steps: (1) formation of bubbles, (2) bubble growth, and (3) violent collapse of bubbles. AC leads to the generation of free radicals, excited chemical entities, speedy reaction rate, and excellent multiphase mixing [52]. Several physicochemical effects are resulted from the ultrasound-induced cavitation. Basically, ultrasound irradiation forms bubbles in a liquid by a process called rectified diffusion (RD) which is governed by area and shell effect [52]. The acoustic cycle is comprised of compression and rarefaction phases, in which gases are diffused in and out of the bubbles. In later phase, the formed bubbles have larger mean surface area compared to the former. Thus, a net flow of gases is always there in the bubbles. In addition to the area effect, the concentration gradient of gases present in fluid shell around bubbles also contributes significantly to the diffusion rate of gases. After reaching a critical size, bubbles collapse too intensely that they generate high-speed microjets, shock waves, and localized high temperature and pressure. Such phenomena are responsible for several unique chemical and physical effects. Theories such as the electric discharge theory, the hot spot theory, and many more have been proposed for understanding chemical effects of ultrasound irradiation, out of which, the hot spot is considered the most favorable one. As per this theory, before the bubble collapsing, bubbles grow under constant temperature condition, but upon the bubble collapse system becomes adiabatic, therefore generating the temperature of a several thousand degrees and the pressure of a several hundreds of atm [53]. Chemical reactions during the AC are significantly affected by the physical effects. Physical effects are generations of microjets of liquid and shock waves. Microjets are generated during asymmetrical bubble collapse in heterogeneous system. These microjets with speed more than $100 \mathrm{~ms}^{-1}$ are directed at the surface of the solids. Both shock waves and microjets can create emulsion in system that contains two immiscible liquids [54].

During the integration of CHLZFO into the GO sheets, $-\mathrm{NH}_{2}$ groups present on CHLZFO and $-\mathrm{COOH}$ function groups can lead to the formation of amide groups and carboxylate groups. Besides, epoxy groups of GO break down into hydroxyl and amino groups. $-\mathrm{COOH}$ can react with amido groups of $\mathrm{CH}$ by glutaraldehyde (cross-linking agent). As per the proposed, possible mechanism of MNC formation, the $-\mathrm{NH}_{2}$ functional groups of CHLZFO biocomposite can undergo reaction with - $\mathrm{COOH}$ and epoxy groups as [55]

(i) hydrogen bonding; $\mathrm{G}-\mathrm{OH} \cdots \mathrm{H}_{2} \mathrm{~N}-\mathrm{R}(\cdots \mathrm{Hbond})$,

(ii) protonated by GO (weakly acidic sites); $\left(-\mathrm{COO}^{-}+\mathrm{H}^{+} ; \mathrm{R}-\mathrm{NH}_{2}+\mathrm{H}^{+} \rightarrow \mathrm{R}-\mathrm{NH}_{3}^{+}\right)$, amides and amino-carboxylate salts as products,

(iii) nucleophile $\left(\mathrm{Nu}^{\ominus}\right)$ attack on epoxy groups, $\mathrm{Nu}^{\ominus}$ having $-\mathrm{NH}_{2}$ groups of $\mathrm{CH}$. 


\subsection{X-Ray Diffraction (XRD)}

XRD was used to investigate the crystal phase and to determine the interlayer spacing for GO. Figure 2 shows the XRD spectra for GO, LZFO, CHLZFO, and CHLZFO-GO. For GO, $2 \theta$ peak can be seen at 9.4563 which confirmed the presence of a well-arranged layer structure with $0.934513 \mathrm{~nm}$ d-spacing $(\mathrm{FWHM}=0.4655)$, along with the (002) orientation (Fig. 2a) [56]. The XRD patterns shown in Fig. 2b depicted the successful fabrication of bare LZFO MNPs, chitosan-coated LZFO NPs, and CHLZFO-GO nanocomposite, respectively. For LZFO, respective $2 \theta$ peak values at $18.2780^{\circ}, 30.1458^{\circ}$, $35.5087^{\circ}, 37.1763^{\circ}, 43.1755^{\circ}, 53.5508^{\circ}, 57.0963^{\circ}$, and $62.7104^{\circ}$ correspond to (111), (220), (311), (222), (400), (222), (400), (422), (511), and (440), crystal planes with no extra peaks observed [10], thus confirming the formation of pure single-phase cubic spinel structure of LZFO devoid of impurities. All the diffraction peaks observed herein are in good agreement with those reported in the literature [10]. The diffraction patterns for CHLZFO and CHLZFO-GO NCs found analogous to the diffraction patterns of LZFO, thereby revealing that no significant variation was observed in the orientation of NPs in the respective nanocomposites. The absence of diffraction peaks of $\mathrm{CH}$ and $\mathrm{GO}$ in respective XRD patterns of CHLZFO and CHLZFO-GO illustrated the successful coating of chitosan on LZFO NPs and the successful exfoliation of GO to a large extent with successful deposition of CHLZFO NPs on it, indicating the formation of nanocomposite [57]. The noise observed in the XRD patterns of CHLZFO and CHLZFO-GO NCs, respectively, is attributed to the amorphous nature of chitosan.
The values of lattice parameter (a), $d$-spacing $\left(d_{\mathrm{hkl}}\right)$, and average crystallite size $(\langle D\rangle)$ for LZFO, CHLZFO, and CHLZFO-GO were determined from the diffraction peaks with $100 \%$ relative intensity corresponding to the crystal plane (311), respectively, using the formulae represented by Eq. (1), Bragg's law Eq. (2), and Eq. (3) (Scherrer's formula) [10]:

$a=\frac{\lambda\left[h^{2}+k^{2}+l^{2}\right]^{1 / 2}}{2 \sin \theta}$

$2 d_{h k l} \sin \theta=n \lambda$

$\langle D\rangle=\frac{K \lambda}{\beta_{h k l} \cos \theta}$

where $a$ is the lattice parameter, $d_{h k l}$ is the interplanar spacing, $\langle D>$ is the average crystallite size, $\lambda(=1.5406 \AA$ for $\mathrm{Cu}-\mathrm{K} \alpha_{1}$ ) is the $\mathrm{X}$-ray radiation, $\theta$ is the Bragg angle (scattering angle), $\beta$ is the full-width half maxima (FWHM), and $K$ is a constant $(=0.94)$.

The calculated values of crystallite size, lattice constant, d-spacing, and volume are shown in Table $1 .<D\rangle$ for CHLZFO-GO, CHLZFO, and LZFO was found in the range of $\sim 22-35 \mathrm{~nm}$. The unit cell parameters of composites of LZFO are found slightly low compared to bare LZFO. These results reveal the presence of a slight strain occurring in composites which distorted the crystal lattice of individual phases to change the lattice parameter confirming the reduction in the size of MNCs, attributed to the high ultrasonication treatment time [58].

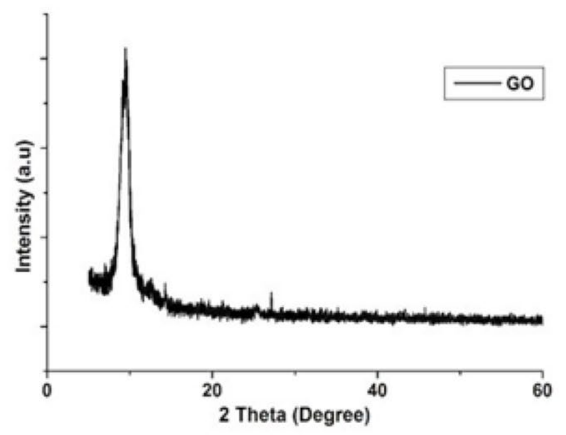

(a)

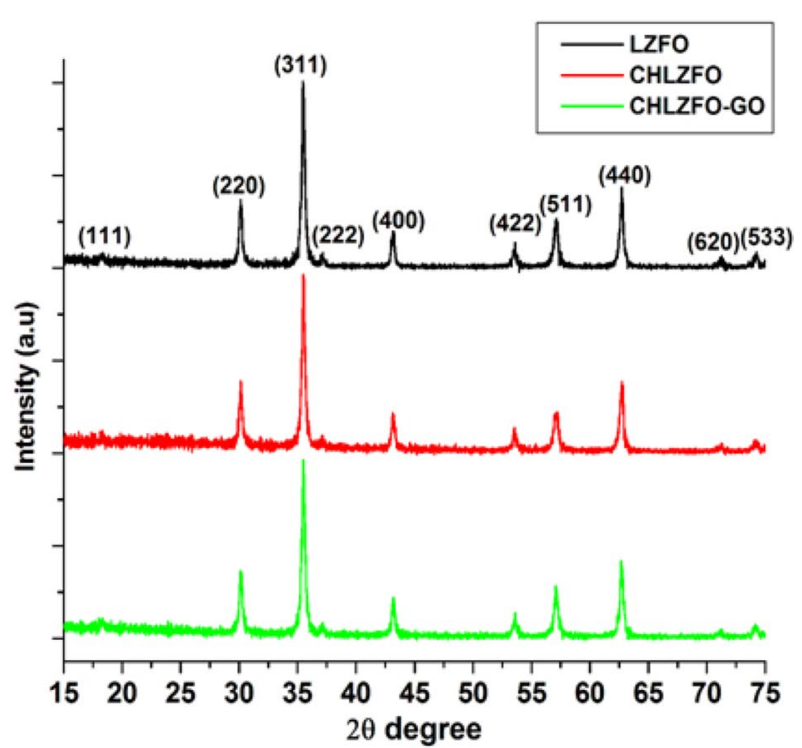

(b)

Fig. 2 XRD diffraction patterns of; a GO, and b LZFO MNPs, CHLZFO, and CHLZFO-GO MNCs 


\subsection{SEM and TEM analysis}

The FESEM images of LZFO NPs, CHLZFO nanocomposite, and CHLZFO-GO are shown in Fig. 3a, b, c: FESEM micrographs of LZFO, CHLZFO, and CHLZFO-GO at $100 \mathrm{~nm}$ scale, respectively, which revealed spherical- and irregular-shaped nanosized morphologies. Agglomerations of the crystallites are also observed, which are attributed to the synthesis technique [59]. No significant information about functionalization can be made out from FESEM images. HRTEM micrographs of bare LZFO MNPs, CHLZFO, and CHLZFO-GO nanocomposite which are shown in Fig. 3d, e, f (HRTEM micrographs of LZFO, CHLZFO, and CHLZFO-GO) indicate spherical- and irregularshaped morphologies of prepared particles with size mostly lying in the range of $\sim 17 \mathrm{~nm}$ to $35 \mathrm{~nm}$. Histograms presenting particle size distribution in Fig. $3 \mathrm{j}-1$ for LZFO, CHLZFO, and CHLZFO-GO clearly indicate that most of the LZFO NPs are of $\sim 33 \mathrm{~nm}$ with standard deviation (SD) of $\sim 10 \mathrm{~nm}$, for CHLZFO mostly are of $\sim 23 \mathrm{~nm}$ with SD $\sim 6.3 \mathrm{~nm}$, and for CHLZFO-GO NPs with a mean diameter of $\sim 19 \mathrm{~nm}$ with $\sim 5.7 \mathrm{~nm}$ SD value. Figure $3 \mathrm{e}$ shows the HRTEM image of CHLZFO which revealed the successful coating of LZFO by biopolymer $\mathrm{CH}$. The micrograph in Fig. 3f depicts the successful entrapping of CHLZFO nanostructured particles inside the GO matrix. Thus, images of HRTEM clearly indicate the successful functionalization of LZFO which confirmed the making of CHLZFO-GO nanocomposites. HRTEM lattice fringe patterns of synthesized bare MNPs and magnetic nanocomposites in Fig. $3 \mathrm{~g}$, h, i (HRTEM lattice fringe patterns of LZFO, CHLZFO, and CHLZFO-GO) showed a close association of the lattice planes of bare LZFO, CHLZFO, and CHLZO-GO, respectively. These HRTEM micrographs also showed that the prepared samples are of crystalline nature. But composites of LZFO compared to it are lesser crystalline, because of the $\mathrm{CH}$ coating and GO matrix [10]. Thus, these micrographs clearly indicate the successful biopolymer coating and incorporation of CHLZFO in the matrix of GO. Crystallite sizes observed in HRTEM analysis are in good agreement with what was calculated from XRD study .

\subsection{Magnetic hysteresis parameters study}

Magnetic parameters, saturation magnetization $\left(M_{s}\right)$, magnetic coercivity $\left(H_{c}\right)$, magnetic remanence $\left(M_{r}\right)$, and squareness $(R)$ of the prepared LZFO NPs, CHLZFO, and CHLZFO-GO nanocomposites are shown in the Table 2. All three samples showed an increase in magnetization value at the low magnetic field $(B)$ and achieve saturation for $B<10$ $\mathrm{kOe}$, revealing the presence of long-range ferromagnetic ordering (shown in Fig. 4: magnetic hysteresis of LZFO, CHLZFO, and CHLZFO-GO, respectively). Maximum saturation magnetization value of $67.1955 \mathrm{emu} / \mathrm{g}$ was observed for bare LZFO with a lower $H_{c}$ value of 94.492 Oe. For CHLZFO nanocomposite and CHLZFO-GO nanocomposite, the observed $M_{s}$ values are $21.597 \mathrm{emu} / \mathrm{g}$ and $19.330 \mathrm{emu} / \mathrm{g}$ to the corresponding $H_{c}$ values $103.213 \mathrm{Oe}$ and $102.771 \mathrm{Oe}$, respectively. The variation in magnetization of the prepared samples is mainly attributed to the change in the particle size and the presence of amorphous polymer and nonmagnetic matrix $[10,60]$. Due to the high surface-to-volume ratio of smaller CHLZFO and CHLZFO-GO NPs, the surface effects like spin disorder and dead layer on the surface arise, leading to the decrease in magnetization value [61]. The higher $M_{s}$ value of bare LZFO MNPs is attributed to their better crystal structures which are inconsistent with HRTEM and XRD data [62]. Other anticipated theories which describe the obtained higher $M_{s}$ value may be superexchange interaction (metal-oxygen-metal), $\mathrm{Zn}^{2+}$ presence on octahedral site, and divergence of Néel's collinear model $[26,63]$. The squareness $\left(R=M_{r}, M_{s}\right)$ values between 0 and 1 tell about the magnetic domain structure. For $\mathrm{M}_{\mathrm{r}} / \mathrm{M}_{\mathrm{s}}<1 / 2$, the material exhibits a multi-domain structure, while for $M_{r} / M_{s} \geq 1 / 2$, the material possesses a single-domain structure [64]. Herein, LZFO MNPs have a high $M_{r} / M_{s}$ value compared to CHLZFO and CHLZFO-GO NCs indicate high magnetocrystalline anisotropy due to their better crystalline nature [65]. Lower $M_{r} / M_{s}$ values for MNCs are attributed to the decrease in crystal order and structure, because of the presence of the amorphous polymer and matrix of GO. R values for the samples prepared in the present work lie from 0.178 to 0.265 , thus revealing the multi-domain structure for the prepared samples. In the literature, ample studies reported an increment in the magnetization of LF on the addition of $\mathrm{Zn}^{2+}$ (mentioned in Table 3). Panchel et al. obtained
Table 1 Structural parameters for pristine LZFO, CHLZFO, and CHLZFO-GO MNCs

\begin{tabular}{lllll}
\hline Sample & $\begin{array}{l}\text { Crystallite } \\
\text { size },<D>(\sim \mathrm{nm})\end{array}$ & $\begin{array}{l}\text { Lattice constant, } \\
a(\mathrm{~nm})\end{array}$ & $d$-spacing, $d_{311}(\AA)$ & $\begin{array}{l}\text { Unit cell } \\
\text { volume }\left(\mathrm{a}^{3}\right) \\
\left(\mathrm{nm}^{3}\right)\end{array}$ \\
\hline LZFO & 35 & 0.8378 & 2.52610 & 0.58806 \\
CHLZFO & 24 & 0.8376 & 2.52551 & 0.58764 \\
CHLZFO-GO & 22 & 0.8375 & 2.52524 & 0.58743 \\
\hline
\end{tabular}



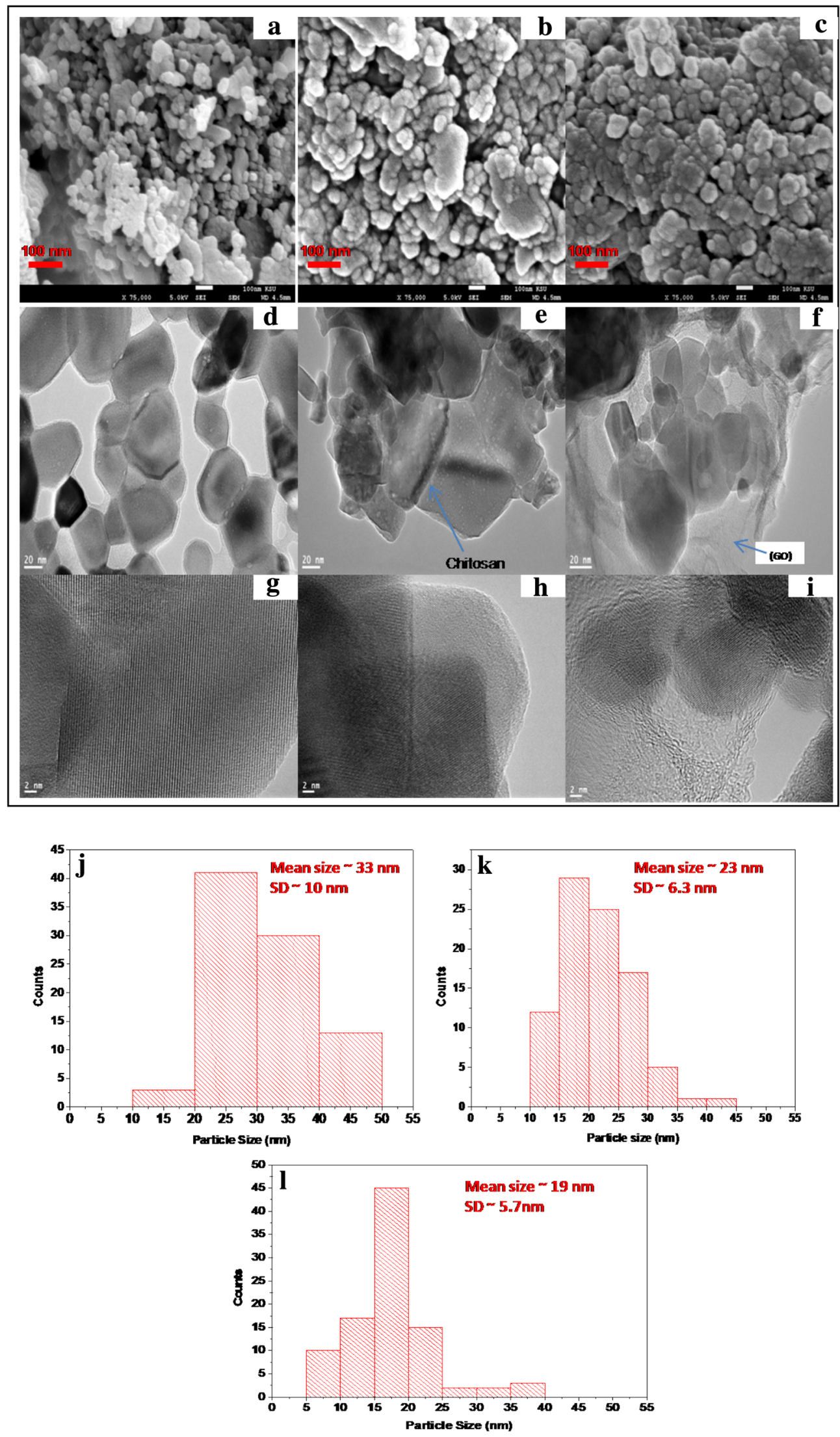

Fig. 3 SEM and TEM micrographs of prepared LZFO MNPs, CHLZFO and CHLZFO-GO MNCs, with particles size distribution for TEM analysis 
Table 2 Magnetic hysteresis parameters of LZFO MNPs, CHLZFO, and CHLZFO-GO MNCs

\begin{tabular}{llrcl}
\hline Sample & $M s(\mathrm{emu} / \mathrm{g})$ & $H c(\mathrm{Oe})$ & $M r(\mathrm{emu} / \mathrm{g})$ & $\begin{array}{l}\text { Squareness } \\
R=M r / M s\end{array}$ \\
\hline LZFO & 67.1955 & 94.492 & 17.851 & 0.265 \\
CHLZFO & 21.597 & 103.213 & 4.117 & 0.190 \\
CHLZFO-GO & 19.330 & 102.771 & 3.440 & 0.178 \\
\hline
\end{tabular}

$M_{s}=64.6 \mathrm{emu} / \mathrm{g}$ for $\mathrm{LF}$ doped with $\mathrm{Zn}=0.25$, synthesized by solgel method. Crystallite sizes calculated by Panchel et al. were in the range $27-38 \mathrm{~nm}$ without calcination [66]. Gee et al. synthesized $\mathrm{Zn}^{2+}$-doped LF for many compositions using the ball milling synthesis route. $M_{s}=80 \mathrm{emu} / \mathrm{g}$ was reported for $\mathrm{Zn}=0.30$, and average crystallite size value was in the range 20-50 $\mathrm{nm}$ [67]. Mallick et al. synthesized mixed lithium zinc ferrite using $\mathrm{Zn}=0.38$ by solgel route followed by 6 -h calcination at $500{ }^{\circ} \mathrm{C}$. The average crystallite size value was in the range of $13-23 \mathrm{~nm}$, and $M_{s}$ values reported are 62 and $95.5 \mathrm{emu} / \mathrm{g}$ at $300 \mathrm{~K}$ and $5 \mathrm{~K}$, respectively [10].

\subsection{CHLZFO-GO-assisted RNA extraction protocol}

SARS-CoV-2s' RNA isolated using CHLZFO-GO MNCs can be examined either by standard RT-PCR (eluted product to be used) or direct RT-PCR (CHLZFO-GO/RNA complex without elution). Extraction protocol is comprised of simple steps like lysis/binding buffer combination with CHLZFOGO NCs in a single step, followed by the throw out of liquid above the formed complex, washing, elution, and finally assembling the extracted RNA for RT-PCR shown in Fig. 5a (schematic representation of CHLZFO-GO MNCs-based viral RNA separation protocol) [8, 12]. The CHLZFO-GO/ RNA complex can be used directly for RT-PCR reaction without elution. In direct subjection, all extracted viral RNAs are subjected to amplification which can lessen the cycle threshold value compared to the usual protocol.

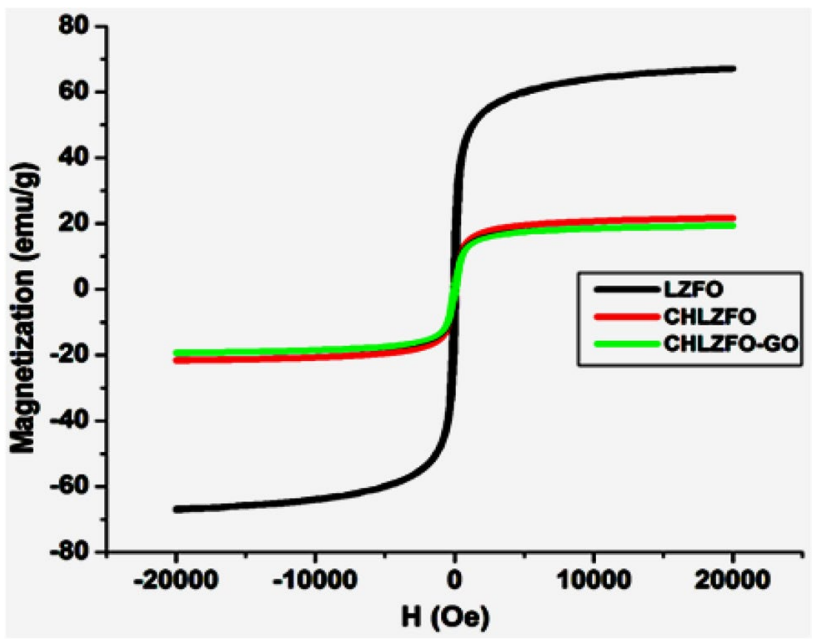

Fig. 4 Magnetic hysteresis of LZFO MNPs, CHLZFO, and CHLZFOGO MNCs

Therefore, in the direct RT-PCR protocol, the possibility of receiving false-negative results can be further reduced. The prepared MNCs can offer the better binding performance with nucleic acid, thereby improving the sensitivity and linearity of the diagnostic technique. Besides excellent performances, other merits of CHLZFO-GO assisted RNA isolation protocol like fewer operating hours, simplicity, and correct diagnosis (Fig. 5b: merits of direct RT-PCR). The current viral extraction protocol can be automated, which will overcome the current issue of centrifugation of conventional technique [8]. The MS of RNA using CHLZFO-GO $\mathrm{MNC}$ is underway and will be reported in the near future.

\subsection{The basic mechanism of magnetic separation}

In MS, targeted biological entities (current research; viral RNA) are separated from their native environment and then studied in a controlled environment. This is done in two steps: (1) the viral RNA tagging with MNPs, and (2) attached viral RNA with MNPs extracted or by applying

Table 3 Correlation between the stoichiometric ratio of zinc and the Ms value obtained in the cited literature and present work

\begin{tabular}{|c|c|c|c|c|c|}
\hline S. No. & $\mathrm{Li}_{0.5-x / 2} \mathrm{Zn}_{x} \mathrm{Fe}_{2.5-x / 2} \mathrm{O}_{4,}(x=\mathrm{Zn}$ content $)$ & Synthesis technique & Calcinated temp. $\left({ }^{\circ} \mathrm{C}\right)$ & $\begin{array}{l}\text { Average crystallite } \\
\text { size }(\mathrm{nm}) \text { (Scherrer) }\end{array}$ & $\begin{array}{l}\text { Magnetic satura- } \\
\text { tion (Ms) (emu } \\
\left.\mathrm{g}^{-1}\right)\end{array}$ \\
\hline 1 & 0.25 & Solgel autocombustion & Without & $27-38$ & 64.6 \\
\hline 2 & 0.30 & Ball milling & $600-1000$ & $20-50$ & 80 \\
\hline 3 & 0.38 & Solgel & 500 & $\sim 15$ & 62 (at $300 \mathrm{~K}$ ) \\
\hline 4 & 0.38 & Solgel & 500 & $\sim 15$ & 95.5 (at $5 \mathrm{~K}$ ) \\
\hline 5 & $\begin{array}{l}0.38 \text { (in this work, prepared ferrite NPs } \\
\text { were integrated in reduced graphene } \\
\text { oxide) }\end{array}$ & $\begin{array}{l}\text { Solgel + ultrasonication } \\
\text { (for functionalization) }\end{array}$ & 500 & $\sim 15$ & 17 at $300 \mathrm{~K}$ ) \\
\hline 6 & 0.34 (present work) & Solgel autocombustion & 500 & $\sim 35 \mathrm{~nm}$ & 67.1955 \\
\hline
\end{tabular}


Fig. 5 a Schematic of CHLZFO-GO MNCs based viral RNA separation protocol, and $\mathbf{b}$ merits of direct RT-PCR

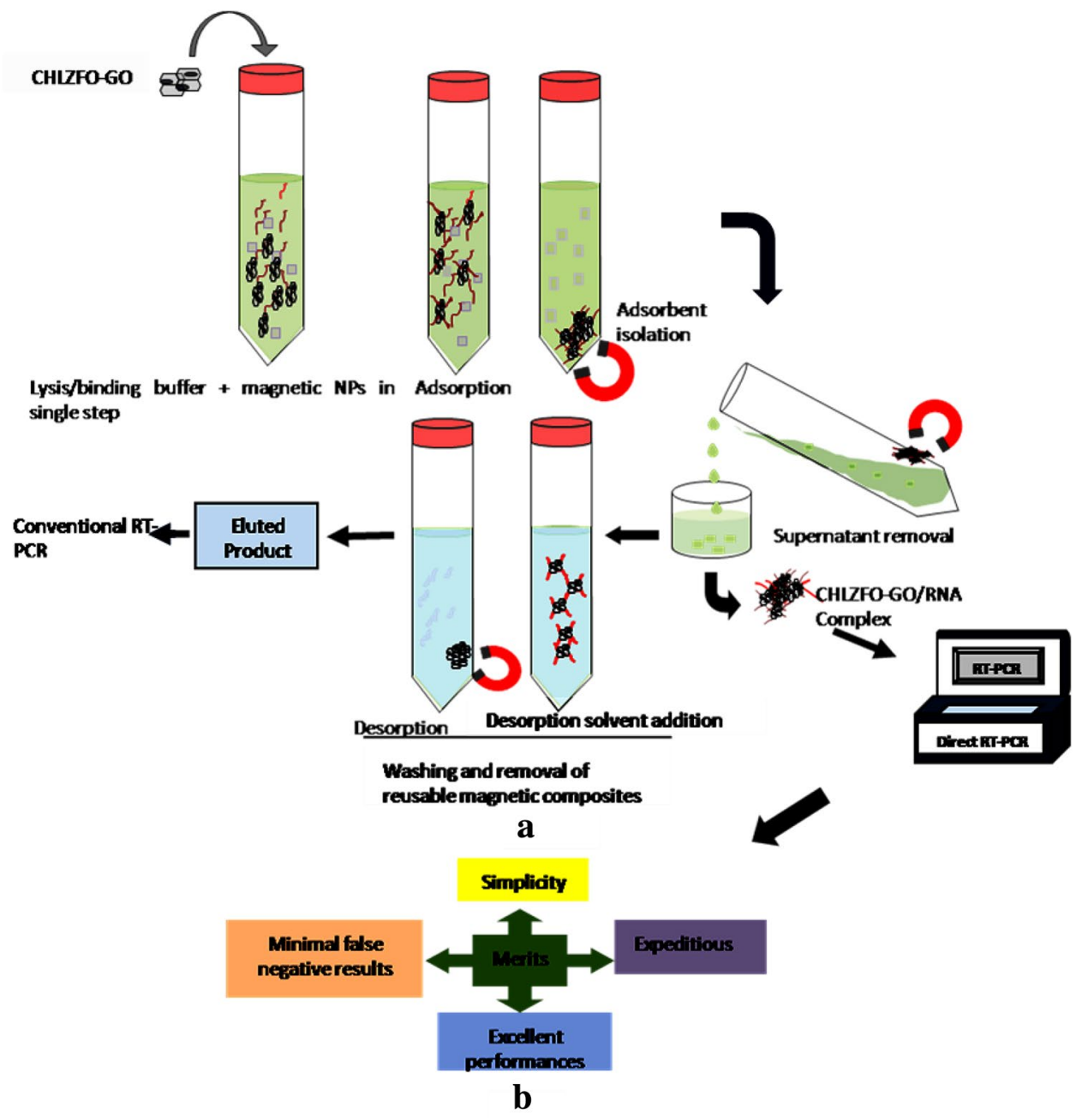

force. Briefly, tagging of viral RNA to MNPs is achieved by preparing a hull of multifunctional MNPs (CHLZFO-GO). For achieving MS, the viral RNA/CHLZFO-GO complex should be in a fluid. Then, the fluid will be exposed to a steep magnetic field gradient. Magnetic force is required to overpower the hydrodynamic drag force and buoyancy force of the fluid. The hydrodynamic drag force is [68]:

$F_{d}=6 \pi \eta R_{m} \Delta v$

where $\eta$ is the viscosity of the fluid, $R_{m}$ is the radius of the multifunction MNPs, $\Delta v=v_{m}-v_{w}$, the difference between velocities of entities and fluid. The radius (size) of the MNPs plays a significant role. Monodisperse particles can provide a very uniform reproducibility of MS. The separation of nanoscale MNPs requires the application of high gradient magnetic separators. The second competing buoyancy force has small effects in the situation and thus can be neglected $[68,69]$. Along with buoyancy, other forces like gravitation and interaction between particles are neglected too [69]. The magnitude of the magnetic force is
$F_{m}=\mu_{o} \chi V_{m}\left(B_{a} \cdot \nabla\right) B_{a}$

where $\mu_{o}$ is the magnetic permeability of free space, $V_{m}$ is the particles' volume, $\chi$ is the magnetic susceptibility, and $B_{a}$ is the applied magnetic field. MNP's motion under magnetic field and viscous fluid can be illustrated by using Newton's law [70]:

$m_{p} \frac{d v_{p}}{d t}=\mu_{o} \chi V_{m}\left(B_{a} \cdot \nabla\right) B_{a}-6 \pi \eta R_{m} \Delta v$

Out of various separator designs [68], a simple design is used herein, where the tagged MNPs are exposed to a permanent magnet (placed sidewise, see Fig. 5a). It is reasonable to use a magnet from the side of the tube holding the sample mixture for aggregating the MNCs about the tube's wall and pouring away the residue. All viral RNA-tagged MNPs get stuck, and the remaining fluid will fly out. Then, magnet can be removed and collected CHLZFO-GO/RNA complex can be washed repeatedly with ethanol (prepared washing buffer sol.); frequency of washing can be twice/ 
thrice. Afterward, the purified SARS-CoV-2 virus RNA can be separated from MNCs by incubating the CHLZFO-GO/ RNA complex in buffer sol. and a certain volume of supernatant can be used for RT-PCR reaction [12]. In the literature, the studies reported regarding the use of MS protocol for SARS-CoV-2 virus extraction indicate that the magnetically assisted RT-PCR protocol is better than the standard one. Different MNPs and MNCs are used for MS protocol for extraction of nucleic acids of SARS-CoV-2 mentioned in Table 3 along with the synthesis route. The research done by Zhao et al. indicates easy, prompt, and efficient detection of SARS-CoV-2s' nucleic acids by poly-NH2-MNP (pcMNPs). pcMNPs-assisted MS protocol is both manual and automated; pcMNPs/RNA complex could be transmitted directly for RT-PCR reaction. Reported extraction time for different samples was approximately 30 min compared to the $2 \mathrm{~h}$ time of the conventional one [12]. Somvanshi et al. showed low-temperature preparation of zinc ferrite whose surface was modified with $-\mathrm{NH} 2$ and $-\mathrm{COOH}$ functional groups. Estimated viral extraction time reported approx. $15 \mathrm{~min}$ [8]. Both Somvanshi et al. and Zhao et al. used TEOS to cover the pristine MNPs with silica and then use APTES and multi-charged polymer $-\mathrm{COOH}$ to introduce $-\mathrm{NH}_{2}$ and -COOH groups. Navas-León D.G. et al. improvised the synthesis technique adopted by Zhao et al. to produce MNPs and MNCs by directly modifying the MNPs' surface with APTES [4]. The possible reason for the formation of the MNCs/SARS-CoV-2-RNA complex reported is the interaction or binding between $-\mathrm{NH}_{2}$ and $-\mathrm{COOH}$ groups with nucleic acids of viral RNA. MNPs that have fabricated so far for COVID-19 are mentioned in Table 4.

Future studies regarding this work include experimental proof to check the followings: (1) affinity of CHLZFO-GO MNC with SARS-CoV-2 RNA, estimated viral extraction time, and efficiency of the CHLZFO-GO-assisted RT-PCR. Besides, a computational study (like molecular docking) can be also conducted to reveal the possible interactions between SARS-CoV-2 RNA and CHLZFO-GO MNC, since it has been done with various MNPs and MNCs against COVID-19 [71, 72]. The future of magnetic separation protocol along with many factors also depends on the separator design. Schematics of separator designs for magnetic separation are presented in Fig. 6 [68]. Figure 6a presents a facile design in which permanent magnet is used as a magnetic field source. This is the design used in this work and the most reported ones in the literature of COVID-19 virus RNA extraction. Figure $6 \mathrm{~b}$ presents a design where the fluid is passed through material like steel wool in the presence of magnetic field. In this, the MNCs-tagged particle stuck with the steel wool, and then on turning the magnetic field off these particles can be flushed out. In the third design presented in Fig. 6c, quadrature setup of magnet is used. Here, tagged particles are attracted toward the wall magnet setup, and then from there they can be flushed out easily on turning the magnetic field off. Optimal designs should work in low-resource settings, i.e., processing large sample volume, and have robust response to external magnetic field [73]. The possible challenge is to make the current protocol reality, particularly on a larger scale. This requires the optimization of optimum parameters of MNCs and separation designs.

\section{Conclusion}

The multifunctional CHLZFO-GO MNC was successfully synthesized using solgel autocombustion and ultrasonication. The nanocrystalline nature, spherical shape, irregular shape and functionalization of the bare MNPs, and formation were authenticated through XRD patterns, FESEM, and HRTEM images. Crystallite sizes for the synthesized MNPs and nanocomposites were found in the nanometric range ( $\sim 19 \mathrm{~nm}$ to $35 \mathrm{~nm}$ ). Investigation of magnetic parameters like nature of hysteresis loop, $M s, H_{c}$, and squareness factor confirmed soft magnetic character, and a decrement in $M_{s}$ values of LZFO, CHLZFO, and CHLZFO-GO from $67.1955 \mathrm{emu} / \mathrm{g}, 21.597 \mathrm{emu} / \mathrm{g}$, and $19.330 \mathrm{emu} / \mathrm{g}$ verifying

Table 4 MNPs with their synthesis routes, encapsulating materials, and functionalization method

\begin{tabular}{|c|c|c|c|c|}
\hline MNPs & Synthesis route & Encapsulating materials & Functionalization method & References \\
\hline Zinc ferrite $\left(\mathrm{ZnFe}_{2} \mathrm{O}_{4}\right)$ & Solgel autocombustion & $\begin{array}{l}\text { Tetraethyl orthosilicate (TEOS), } \\
\text { (3-aminopropyl)triethoxysilane } \\
\text { (APTES), -COOH-loaded polyvi- } \\
\text { nyl alcohol (PVA) }\end{array}$ & Post-synthesis (ultrasonication) & [8] \\
\hline Magnetite $\left(\mathrm{Fe}_{3} \mathrm{O}_{4}\right)$ & Co-precipitation method & $\begin{array}{l}\text { TEOS, APTES, poly(amino ester) } \\
\text { loaded with many -COOH groups }\end{array}$ & $\begin{array}{l}\text { Post-synthesis (one-step incubation) } \\
\text { (sonication) }\end{array}$ & [12] \\
\hline Magnetite $\left(\mathrm{Fe}_{3} \mathrm{O}_{4}\right)$ & Co-precipitation method & $\begin{array}{l}\text { APTES (- } \mathrm{NH}_{2} \text { group), poly(amino } \\
\text { ester), no use of TEOS }\end{array}$ & $\begin{array}{l}\text { Post-synthesis (one-step incubation) } \\
\text { (sonication) }\end{array}$ & {$[4]$} \\
\hline $\mathrm{Li}_{0.33} \mathrm{Zn}_{0.34} \mathrm{Fe}_{2.33} \mathrm{O}_{4}(\mathrm{LZFO})$ & Solgel autocombustion & $\begin{array}{l}\text { Chitosan }\left(-\mathrm{NH}_{2}\right) \text {, graphene oxide }(- \\
\mathrm{OH},-\mathrm{COOH})\end{array}$ & Post-synthesis (ultrasonication) & (this work) \\
\hline
\end{tabular}


Fig. 6 Schematics of various separator designs for magnetic separation

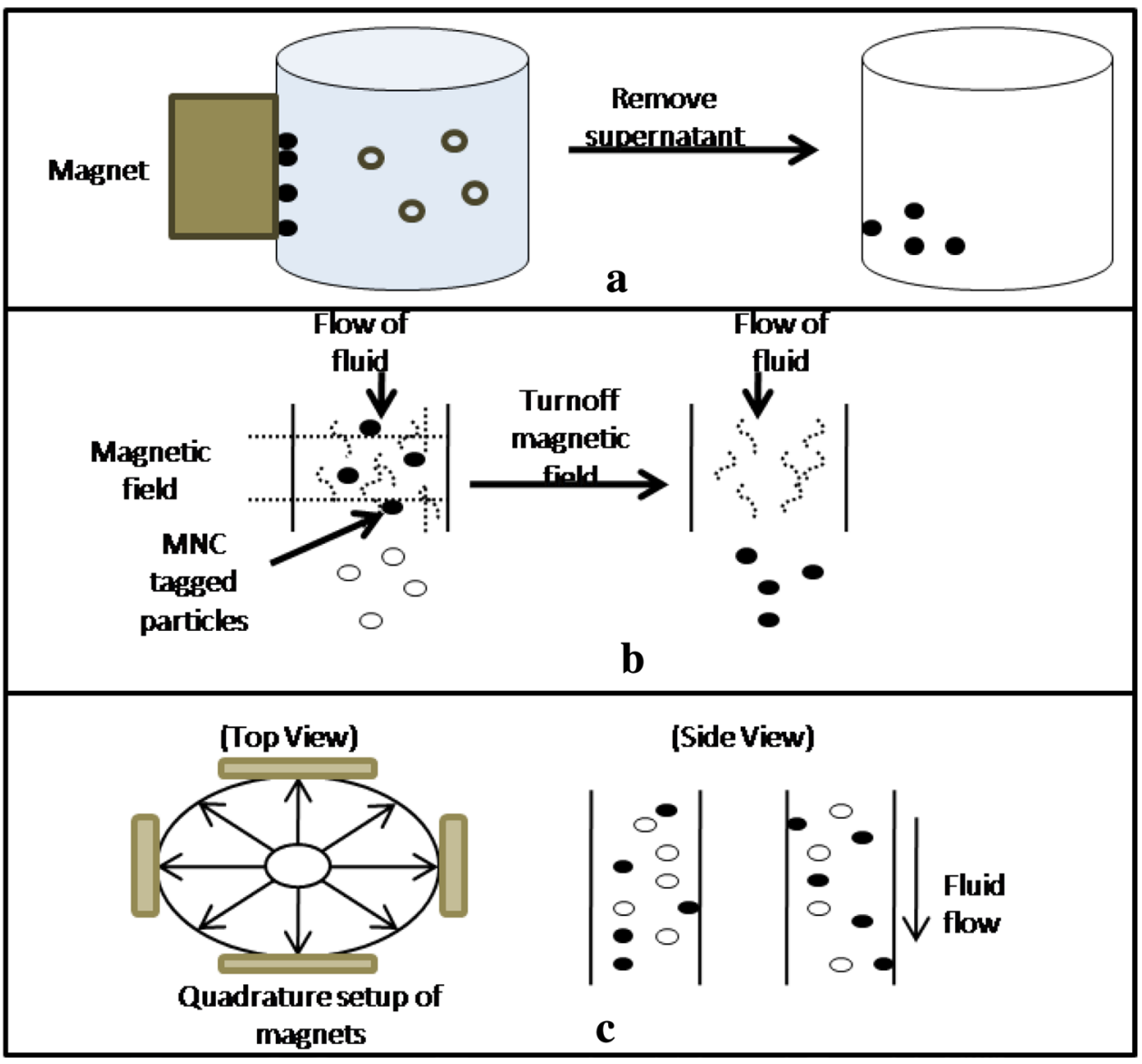

size decrement, successful CH coating, and GO integration. The observed magnetization values are suitable for the efficient and robust RNA extraction procedure for the potential detection of SARS-CoV-2 in COVID-19 patients. The MNC-assisted RT-PCR technique is simple, economical, time-saving, and much effective in detection and thus can be seen as a potential substitute for conventional RT-PCR techniques. Implementation of the proposed protocol for clinical purposes needs more studies both on fundamental and on technical levels. MNC-based extraction can be an innovative technology for isolating RNA from swabs for fast COVID 19 tests at a larger scale.

\section{References}

1. https://www.who.int/en/activities/tracking-SARS-CoV-2-variants/ (2021)

2. D.J.D.R. Bandoy, B.C. Weimer, Analysis of SARS-CoV-2 genomic epidemiology reveals disease transmission coupled to variant emergence and allelic variation. Sci. Rep. 11, 7380 (2021). https://doi.org/10.1038/s41598-021-86265-4

3. L. Bian, F. Gao, J. Zhang, Q. He, Q. Mao, Xu. Miao, Z. Liang, Effects of SARS-CoV-2 variants on vaccine efficacy and response strategies. Expert Rev. Vaccines (2021). https://doi.org/10.1080/ 14760584.2021.1903879

4. J.C. Chacón-Torres, C. Reinoso, D.G. Navas-León et al., Optimized and scalable synthesis of magnetic nanoparticles for RNA extraction in response to developing countries' needs in the detection and control of SARS-CoV-2. Sci. Rep. 10, 19004 (2020). https://doi.org/10.1038/s41598-020-75798-9

5. A. Afzal, Molecular diagnostic technologies for COVID-19 Limitations and challenges. J. Adv. Res. 26: 149-159 (2020). https:// doi.org/10.1016/j.jare.2020.08.002

6. S. Esposito et al., Separation of biological entities from human blood by using magnetic nanocomposites obtained from zeolite precursors. Molecules (Basel, Switzerland) 25(8), 1803 (2020). https://doi.org/10.3390/molecules25081803

7. M. Franzreb, M. Siemann-Herzberg, T.J. Hobley, O.R.T. Thomas, Protein purification using magnetic adsorbent particles. Appl. Microbiol. Biotechnol. 70, 505-516 (2006). https:// doi.org/10.1007/s00253-006-0344-3

8. B. Sandeep, S. Somvanshi et al., Multifunctional nano-magnetic particles assisted viral RNA-extraction protocol for potential detection of COVID-19. Mater. Res. Innov. 25(3), 1-6 (2020). https://doi.org/10.1080/14328917.2020.1769350

9. A. Islam A, Z. Ahsan Md, Plausible approach for rapid detection of SARS-CoV-2 virus by magnetic nanoparticle based biosensors Md. J. Nanosci. Nanotechnol. 6(2): 6-13 (2020). https:// doi.org/10.11648/j.ajn.20200602.11

10. A. Mallick, A.S. Mahapatra, A. Mitra, J.M. Greneche, R.S. Ningthoujam, P.K. Chakrabarti, Magnetic properties and biomedical applications in hyperthermia of lithium zinc ferrite 
nanoparticles integrated with reduced graphene oxide. J. Appl. Phys. 123, 055103 (2018). https://doi.org/10.1063/1.5009823

11. T. Lage, R.O. Rodrigues, S. Catarino, J. Gallo, M. BañobreLópez, G. Minas, Graphene-based magnetic nanoparticles for theranostics: an overview for their potential in clinical application. Nanomaterials 11, 1073 (2021). https://doi.org/10.3390/ nano11051073

12. Z. Zhao, H. Cui, W. Song, X. Ru, W. Zhou, X. Yu A simple magnetic nanoparticles-based viral RNA extraction method for efficient detection of SARS-CoV-2. bioRxiv preprint. (2020). https://doi.org/10.1101/2020.02.22.961268

13. https://dst.gov.in/sree-chitra-tirunal-institute-develops-magne tic-nanoparticle-based-rna-extraction-kit-pcr-and-lamp (2021).

14. https://www.nanowerk.com/nanotechnology-news $2 /$ newsid= 54893.php(2020)

15. S. Klein, G.T. Muller, D. Khalid et al., SARS-CoV-2 RNA extraction using magnetic beads for rapid large scale testing by RT-qPCR and RT-LAMP. Viruses. 12 (8), 863 (2020).https:// doi.org/10.3390/v12080863

16. A. Milewska, Y. Chi, A. Szczepanski, E. Duran et al., HTCC as a polymeric inhibitor of SARS-CoV-2 and MERS-CoV. J. Virol. 95(4), e01622-20 (2021). https://doi.org/10.1128/JVI.01622-20

17. L. Farzin, S. Sadjadi, A. Sheini et al., A nanoscale genosensor for early detection of COVID-19 by voltammetric determination of RNA-dependent RNA polymerase (RdRP) sequence of SARS-CoV-2 virus. Microchim. Acta. 188, 121 (2021). https:// doi.org/10.1007/s00604-021-04773-6

18. M.R. Hathout, H.D. Kassem, Positively charged electroceutical spun chitosan nanofibers can protect health care providers from COVID-19 infection: an opinion. Front. Bioeng. Biotechnol. 8, 885 (2020). https://doi.org/10.3389/fbioe.2020.00885

19. A.M. Unal et al., Graphene oxide nanosheets interact and interfere with SARS-CoV-2 surface proteins and cell receptors to inhibit infectivity. Small 2101483, 1-13 (2021). https://doi.org/ $10.1002 / \mathrm{smll} .202101483$

20. A. Ali, S. Ahmed, A review on chitosan and its nanocomposites in drug delivery. Int. J. Biol. Macromol. 109, 273-286 (2017). https://doi.org/10.1016/j.ijbiomac.2017.12.0780141-8130

21. T.J. Madera-Santana, C.H. Herrera-Méndez, J.R. RodríguezNúñez, An overview of the chemical modifications of chitosan and their advantages. Green Mater. 6(4), 131-142 (2018). https://doi.org/10.1680/jgrma.18.00053

22. G. Alitongbieke, X.M. Li, Q.C. Wu, Z.C. Lin, J.F. Huang, Y. Xue, J.N. Liu, J.M. Lin, T. Pan, Y-X. Chen, Y. Su, G-G. Zhang, B. Leng, S-W. Liu, Y-T. Pan, Effect of $\beta$-chitosan on the binding interaction between SARS-CoV-2 S-RBD and ACE. (2020) https://doi.org/10.1101/2020.07.31.229781

23. I.S. Donskyi, C. Nie, K. Ludwig, J. Trimpert, R. Ahmed, E. Quaas, K. Achazi, J. Radnik, M. Adeli, R. Haag, K. Osterrieder, SARS-CoV-2 Inhibitors: graphene sheets with defined dual functionalities for the strong SARS-CoV-2 interactions. Small 17(11), 2170046 (2021). https://doi.org/10.1002/smll. 202170046

24. P. Kumar Raghav, S. Mohanty, Are graphene and graphenederived products capable of preventing COVID-19 infection? Med. Hypotheses. 144, 110031 (2020). https://doi.org/10.1016/j. mehy.2020.110031

25. M. Amiri, M.S. Niasari, A. Akbari, Magnetic nanocarriers: evolution of spinel ferrites for medical applications. J. Colloid Interface Sci. (2019). https://doi.org/10.1016/j.cis.2019.01.003

26. P. Kishan, D.R. Sagar, S.N. Chatterjee et al., Curie temperatures and $0^{\circ} \mathrm{K}$ magnetic moments of zinc-substituted lithium ferrites. Bull. Mater. Sci. 6, 39-45 (1984). https://doi.org/10.1007/BF027 44167

27. L. Mohammed, H.G. Gomaa, D. Ragab, J. Zhu, Magnetic nanoparticles for environmental and biomedical applications: a review.
J. partic. 921, 1-14 (2016). https://doi.org/10.1016/j.partic.2016. 06.001

28. R. Valenzuela, Novel applications of ferrites. Phys. Res. Int. 2012, 9 (2012). https://doi.org/10.1155/2012/591839

29. M. Airimioaei, C.E. Ciomaga, N. Apostolescu et al., Synthesis and functional properties of the $\mathrm{Ni}_{1-x} \mathrm{Mn}_{\mathrm{x}} \mathrm{Fe}_{2} \mathrm{O}_{4}$ ferrites. J. Alloys Compd. 509(31), 8065-8072 (2011). https://doi.org/10.1016/j. jallcom.2011.05.034

30. A.C.F.M. Costa, M.R. Morelli, R.H.G.A. Kiminami, Microstructure and magnetic properties of $\mathrm{Ni}_{1-\mathrm{x}} \mathrm{Zn}_{\mathrm{x}} \mathrm{Fe}_{2} \mathrm{O}_{4}$ synthesized by combustion reaction. J. Mater. Sci. 42(3), 779-783 (2007)

31. M. George, A. Mary John, S.S. Nair et al., Finite size effects on the structural and magnetic properties of sol-gel synthesized $\mathrm{NiFe}_{2} \mathrm{O}_{4}$ powders. J. Magn. Magn. Mater. 302(1), 190-195 (2006). https:// doi.org/10.1016/j.jmmm.2005.08.029

32. A.S. Mukasyan, P. Epstein, P. Dinka, Solution combustion synthesis of nanomaterials. P. Combust. Inst. 31(2), 1789-1795 (2007). https://doi.org/10.1016/j.proci.2006.07.052

33. D.C. Marcano, D.V. Kosynkin, J.M. Berlin, A. Sinitskii, Z. Sun, A. Slesarev, L.B. Alemany, W. Lu, J.M. Tour, Improved synthesis of graphene oxide. ACS Nano. 4(8), 4806-4814 (2010). https:// doi.org/10.1021/nn1006368

34. R. Jasrotia, P. Virender, Singh, R. Kumar, M. Singh, Raman spectra of sol-gel auto-combustion synthesized $\mathrm{Mg}-\mathrm{Ag}-\mathrm{Mn}$ and $\mathrm{Ba}-$ Nd-Cd-In ferrite based nanomaterials, Ceram. Int. (2019). https:// doi.org/10.1016/j.ceramint.2019.09.012

35. K.S. Kiran, N. Thakur, Structural and electrical properties of chitosan - spinel $\mathrm{MnFe}_{2} \mathrm{O}_{4}$ biocomposites. AIP Conf. Proc. 2220, 020182-1-020182-6 (2018). https://doi.org/10.1063/5.0002383

36. M.H. Habibi, F. Fakhri, Sol-gel combustion synthesis and characterization of nanostructure copper chromite spinel. J Therm Anal Calorim 115, 1329-1333 (2014). https://doi.org/10.1007/ s10973-013-3480-x

37. M. Sharma, M. Pathak, P. Kapoor, The Sol-Gel method: pathway to ultrapure and homogeneous mixed metal oxide nanoparticles Asian. J. Chem. 30(7), 1405-1412 (2018). https://doi.org/10. 14233/ajchem.2018.20845

38. R.V. Bhagwat, V.A. Humbe, D.S. More, M.K. Jadhav, Sol-gel auto combustion synthesis and characterizations of cobalt ferrite nanoparticles: different fuels approach. Mater. Sci. Eng: B 248, 114388 (2019). https://doi.org/10.1016/j.mseb.2019.114388

39. J.Y. Patil, M.S. Khandekar, I.S. Mulla et al., Combustion synthesis of magnesium ferrite as liquid petroleum gas (LPG) sensor: effect of sintering temperature. Curr. Appl. Phys. 12(1), 319-324 (2012). https://doi.org/10.1016/j.cap.2011.06.029

40. M. Sertkol, Y. Kōseoglu, A. Baykal, et al. Synthesis and magnetic characterization of $\mathrm{Zn}_{0.7} \mathrm{Ni}_{0.3} \mathrm{Fe}_{2} \mathrm{O}_{4}$ nano particles via microwaveassisted combustion route. J. Magn. Magn. Mater. 322(7), 866871 (2009). https://doi.org/10.1016/j.jmmm.2009.11.018

41. T.T.L. Nguyen, H.T.L. Nguyen, H.T. Nguyen et al., A facile synthesis, characterization, and photocatalytic activity of magnesium ferrite nanoparticles via the solution combustion method. J. Chem. 2019, 3428681 (2019). https://doi.org/10.1155/2019/3428681

42. S. Verma, J. Karande, A. Patidar et al., Low-temperature synthesis of nanocrystalline powders of lithium ferrite by an autocombustion method using citric acid and glycine. Mater. Lett. 59(21), 2630-2633 (2005). https://doi.org/10.1016/j.matlet.2005.04.005

43. H. Xue, Z. Li, X. Wang et al., Facile synthesis of nanocrystalline zinc ferrite via self-propagating combustion method. Mater. Lett. 61(2), 347-350 (2007)

44. Z. Yue, W. Guo, J. Zhou et al., Synthesis of nanocrystalline ferrites by sol-gel combustion process: the influence of $\mathrm{pH}$ value of solution. J. Magn. Magn. Mater. 270(1-2), 216-223 (2004). https://doi.org/10.1016/j.jmmm.2003.08.025

45. H. Waqas, A.H. Qureshi, Influence of $\mathrm{pH}$ on nanosized $\mathrm{Mn}-\mathrm{Zn}$ ferrite synthesized by sol-gel auto combustion process. J. Therm. 
Anal. Calorim. 98(2), 355-360 (2009). https://doi.org/10.1007/ s10973-009-0289-8

46. S.M. Hashemi, S. Hasani, K.J. Ardakani, F. Davar, The effect of simultaneous addition of ethylene glycol and agarose on the structural and magnetic properties of $\mathrm{CoFe}_{2} \mathrm{O}_{4}$ nanoparticles prepared by the sol-gel auto-combustion method. J. Magn. Magn. Mater. 492(5), 165-714 (2019). https://doi.org/10.1016/j.jmmm.2019. 165714

47. A.V. Kadu, S.V. Jagtap, G.N. Chaudhari. Studies on the preparation and ethanol gas sensing properties of spinel $\mathrm{Zn}_{06} \mathrm{Mn}_{0.4} \mathrm{Fe}_{2} \mathrm{O}_{4}$ nanomaterials. Current Appl. Phys. 9(6), 1246-1251 (2009). https://doi.org/10.1016/j.cap.2009.02.001

48. P. Vijaya Bhasker Reddy, B. Ramesh, R.C. Gopal, Electrical conductivity and dielectric properties of zinc substituted lithium ferrites prepared by sol-gel method. Physica B: Condens. Matter. 405(7), 1852-2185 (2010). https://doi.org/10.1016/j.physb.2010. 01.062

49. A.C.F.M. Costa, D.A. Vieira, V.J. Silva et al., Synthesis of the $\mathrm{Ni}-\mathrm{Zn}-\mathrm{Sm}$ ferrites using microwaves energy. J. Alloy Compd. 483(1-2), 37-39 (2009). https://doi.org/10.1016/j.jallcom.2008. 08.096

50. S.E. Alhwaitat, H.S. Mahmood, A.M. Hussein, M. Mohsen et al., Effects of synthesis route on the structural and magnetic properties of $\mathrm{Ba}_{3} \mathrm{Zn}_{2} \mathrm{Fe}_{24} \mathrm{O}_{41}\left(\mathrm{Zn}_{2} \mathrm{Z}\right)$ nanocrystalline hexaferrites. Ceram. Int. 44(1), 779-787 (2017). https://doi.org/10.1016/j.ceramint. 2017.09.247

51. L. Yu, S. Cao, Y. Liu et al., Thermal and structural analysis on the nanocrystalline NiCuZn ferrite synthesis in different atmospheres. J. Magn. Magn. Mater. 301(1), 100-106 (2006). https://doi.org/ 10.1016/j.jmmm.2005.06.020

52. E. Kuna, R. Behling, S. Valange, G. Chatel, C.J. Colmenares, Sonocatalysis: a potential sustainable pathway for the valorization of lignocellulosic biomass and derivatives. Top. Curr. Chem. 375(2), 41 (2017)

53. M.N. Bahadur, F. Chowdhury, Obaidullah Md, Hossain et al., (2019) Ultrasonic-assisted synthesis, characterization, and photocatalytic application of $\mathrm{SiO} 2 @ \mathrm{TiO} 2$ core-shell nanocomposite particles. J. Nanomater. 1-11 (2019). https://doi.org/10.1155/ $2019 / 6368789$

54. R. Ambati, R.P. Gogate, Ultrasound assisted synthesis of iron doped TiO2 catalysis. Ultrason. Sonochem. 40, 91-100 (2018)

55. A.N. Travlou, Z.G. Kyzas, K.N. Lazaridis, A.E. Deliyanni, Functionalization of graphite oxide with magnetic chitosan for the preparation of a nanocomposite dye adsorbent. Langmuir $\mathbf{2 9}$, 1657-1668 (2013). https://doi.org/10.1021/la304696y

56. N.M.S.Hidayah, W-W. Liu, C-W. Lai, N.Z. Noriman, C.S Khe et al., Comparison on graphite, graphene oxide and reduced graphene oxide: synthesis and characterization. AIP Conf. Proc. 1892, 150002, (2017) https://doi.org/10.1063/1.5005764

57. R. Bhattacharyya, O. Prakash, S. Roy et al., Graphene oxideferrite hybrid framework as enhanced broadband absorption in gigahertz frequencies. Sci. Rep. 9, 12111 (2019). https://doi.org/ 10.1038/s41598-019-48487-5

58. S. Sompech, A. Srion, A. Nuntiya, The effect of ultrasonic treatment on the particle size and specific surface area of $\mathrm{LaCoO} 3$. Procedia Eng. 32, 1012-1018 (2012). https://doi.org/10.1016/j. proeng.2012.02.047

59. A. Sukta, G. Mezinskis, Sol-gel auto-combustion synthesis of spinel-type ferrite nanomaterials. Front. Mater. Sci. 6(2), 128-141 (2012). https://doi.org/10.1007/s11706-012-0167-3
60. Q. Li, C.W. Kartikowati, S. Horie et al., Correlation between particle size/domain structure and magnetic properties of highly crystalline $\mathrm{Fe}_{3} \mathrm{O}_{4}$ nanoparticles. Sci. Rep. 7, 9894 (2017). https:// doi.org/10.1038/s41598-017-09897-5

61. M.D. Coutinho, S.M.V. Verenkar, Spin canting and surface spin disorder in Ni-substituted Co-Cd ferrite nanoparticles synthesized by fuel deficient combustion method. J. All. Com. 782, 392-403 (2018). https://doi.org/10.1016/j.allcom.2018.12.179

62. D. Cao, H. Li, L. Pan et al., High saturation magnetization of $\gamma-\mathrm{Fe}_{2} \mathrm{O}_{3}$ nano-particles by a facile one-step synthesis approach. Sci. Rep. 6, 32360 (2016). https://doi.org/10.1038/srep32360

63. M.S Patange, S.S Desai, S.M. Meena et al., Random site occupancy induced disordered Neẻl type collinear spin alignment in heterovalent $\mathrm{zn}^{2+}-\mathrm{Ti}^{4+}$ substituted CoFe2O4, RSC Adv. 5, 9148291492 (2015). https://doi.org/10.1039/C5RA21522F

64. S. Dagar, A. Hooda, S. Khasa, M. Malik, Rietveld refinement, dielectric and magnetic properties of NBT-Spinel ferrite composites. J. Alloys Compd. 806, 737-752 (2019). https://doi.org/ 10.1016/j.jallcom.2019.07.178

65. K. Praveena, K.B.R. Varma, Improved magneto-electric response in $\mathrm{Na}_{0.5} \mathrm{Bi}_{0.5} \mathrm{TiO}_{3}-\mathrm{MnFe}_{2} \mathrm{O}_{4}$ composites. J. Mater. Sci. Mater. Electron. 25, 111-116 (2014). https://doi.org/10.1007/ s10854-013-1557-8

66. S. Panchel, S. Raghuvanshi, K. Gehlot, F. Mazaleyrat, S.N. Kane. Cationic distribution assisted tuning of magnetic properties of $\mathrm{Li}_{0.5-\mathrm{x} / 2} \mathrm{Zn}_{\mathrm{x}} \mathrm{Fe}_{2.5-\mathrm{x} / 2} \mathrm{O}_{4}$, AIP Adv. 6, 055930 (2016). https://doi.org/ $10.1063 / 1.4944517$

67. S.H. Gee, Y.K., M.H. Hong Park, D.W. Erickson, P.J Lamb, J Sur, Synthesis of nanosized $\left(\mathrm{Li}_{0.5 \mathrm{x}} \mathrm{Fe}_{0.5 \mathrm{x}} \mathrm{Zn}_{1-\mathrm{x}}\right) \mathrm{Fe}_{2} \mathrm{O}_{4}$ particles and magnetic properties, J. Appl. Phys. 91, 7586 (2002). https:// doi.org/10.1063/1.1453931

68. M. Benz Superparamagnetism: theory and applications, 1-26 (2012)

69. W.T. Harvey, A.M. Carabelli, B. Jackson et al., SARS-CoV-2 variants, spike mutations and immune escape. Nat. Rev. Microbiol. 19(409-42), 4 (2021). https://doi.org/10.1038/ s41579-021-00573-02

70. W. Wei, Z. Wang, Investigation of magnetic nanoparticle motion under a gradient magnetic field by an electromagnet. J. Nanomater. 2018, 5 (2018). https://doi.org/10.1155/2018/6246917

71. S. Dacrory, Antimicrobial activity, DFT calculations, and molecular docking of dialdehyde cellulose/graphene oxide film against Covid-19. J. Polym. Environ. 29, 2248-2260 (2021). https://doi. org/10.1007/s10924-020-02039-5

72. V. Sankar, S.S. Lakshmi, M.D. Ragupathy, Role of nanotechnology in facing SARS-CoV-2 pandemic: solving crux of the matter with a hopeful arrow in the quiver. Sens. Int. 2, 100096 (2021). https://doi.org/10.1016/j.sintl.2021.100096

73. I.S. Pearlman, M. Leelawong, F.R. Haselton et al, Low-resource nucleic acid extraction method enabled by high-gradient magnetic separation. ACS Appl. Mater. Interfaces 12: 12457-12467 (2020). https://doi.org/10.1021/acsami.9b21564

Publisher's Note Springer Nature remains neutral with regard to jurisdictional claims in published maps and institutional affiliations. 